\title{
BMJ Open Health profiles and racial disparities among individuals on probation in Hennepin County, Minnesota, 2016: a cross-sectional study
}

\author{
Marin Olson (D) , ${ }^{1,2}$ Rebecca J Shlafer, ${ }^{3}$ Peter Bodurtha, ${ }^{4}$ Jonathan Watkins, ${ }^{5}$ \\ Courtney Hougham, ${ }^{6}$ Tyler N A Winkelman ${ }^{4,7}$
}

To cite: Olson M, Shlafer RJ, Bodurtha P, et al. Health profiles and racial disparities among individuals on probation in Hennepin County, Minnesota, 2016: a crosssectional study. BMJ Open 2021;11:e047930. doi:10.1136/ bmjopen-2020-047930

- Prepublication history and additional supplemental material for this paper are available online. To view these files, please visit the journal online (http://dx.doi.org/10.1136/ bmjopen-2020-047930).

Received 16 December 2020 Accepted 12 August 2021

Check for updates

(C) Author(s) (or their employer(s)) 2021. Re-use permitted under CC BY-NC. No commercial re-use. See rights and permissions. Published by BMJ.

For numbered affiliations see end of article.

Correspondence to Dr Tyler N A Winkelman; tyler.winkelman@hcmed.org

\section{ABSTRACT}

Objectives To estimate the health characteristics and racial/ethnic health disparities among a probation cohort in Hennepin County. We hypothesised the probation population would have higher health needs compared with the general population as well as significant racial/ethnic health disparities.

Design Cross-sectional study using linked administrative records.

Participants of 7992 eligible individuals, 5873 met inclusion criteria of 6 or more months of eligibility for a full-benefit Minnesota healthcare plan.

Setting Probation system in Hennepin County in 2016. Outcomes We compared health condition prevalence among our probation cohort with survey data from the general population and analysed by race/ethnicity. We also measured sociodemographic characteristics, including the use of safety-net services.

Results Individuals were predominantly male (80.5\%), young (mean age: 35.5 years), and disproportionately black or African American (52.9\%). A majority of individuals enrolled in Medicaid were eligible via Medicaid expansion (65.9\%). Compared with the general population, individuals on probation had higher rates of substance use disorders $(66.5 \%$ vs $8.1 \%)$, mental illness $(55.3 \%$ vs $14.4 \%$ ) and many physical conditions (eg, asthma: $17.0 \%$ vs $12.5 \%$, chronic kidney disease: $5.8 \%$ vs $0.2 \%$ ). White individuals on probation were significantly more likely than black or African American individuals to have a diagnosed substance use disorder $(71.6 \%$ vs $62.0 \%)$ or mental health disorder (64.9\% vs $48.5 \%)$, but fewer chronic physical health conditions (average: 0.52 vs 0.73 chronic physical conditions).

Conclusions Individuals on probation have high health needs, which vary substantially by race/ethnicity. Without attention to this variation, interventions to address health conditions in this population could worsen racial/ethnic disparities.

\section{INTRODUCTION}

More than 3.5million individuals are on probation in the USA, accounting for nearly 1 in 70 US citizens and totalling more than jail and prison populations combined. ${ }^{1-3}$ Probation is an alternative to incarceration,
Strengths and limitations of this study

- This study describes the probation population using linked county administrative and healthcare claims data sets.

- Health conditions were determined by diagnosis codes from healthcare claims, and probation status was determined by county data, eliminating recall and social desirability bias.

- Analysing linked data sets provides county-specific, granular information that can inform local policies.

- Results were restricted to individuals in Hennepin County, Minnesota, and may not be generalisable.

meaning continued criminal justice reform measures may shift more individuals to serve sentences outside of prisons and jails. ${ }^{4}$ People on probation are disproportionately from racial and ethnic minority groups and have higher rates of many health conditions, including physical health, mental health and substance use conditions, compared with the general population. ${ }^{5}{ }^{6}$ Nearly one-quarter of people recently on probation report having a disability. ${ }^{7}$ Age-adjusted studies have also shown that individuals on probation have a higher mortality rate than the general public. ${ }^{8}$ In addition to their complex health needs, individuals on probation also experience increased barriers to accessing outpatient medical care and disproportionately use emergency department and inpatient care, regardless of insurance status. ${ }^{6}$ Justiceinvolved populations also have considerable social barriers, with high rates of housing insecurity, poverty and unemployment. ${ }^{9}$

To date, estimates of the health and healthcare use patterns of probation populations have largely relied on national survey data and include both people currently on probation as well as people who were recently on probation. ${ }^{67}$ These studies are scarce in number 
and limited by self-reporting bias, social desirability bias, and an inability to verify both disease diagnoses and probation status. Additionally, these approaches require primary data collection and do not capture local patterns in disease prevalence or corrections practices. Local and regional data are needed to inform tailored health interventions that improve access and health outcomes for individuals on probation.

Relative to periods of incarceration, there are unique challenges and opportunities to improve care and reduce health inequities during probation. While healthcare is constitutionally required for individuals who are incarcerated, no such obligation exists for individuals on probation. ${ }^{10}$ Yet, because individuals on probation are not incarcerated, they are able to access services in the community that do not exist in jails and prisons. For example, the Medicaid inmate exclusion policy prohibits incarcerated individuals from receiving care through Medicaid. ${ }^{11}$ Because people on probation serve sentences in the community, they are able to maintain Medicaid eligibility and enrolment. Thus, individuals on probation represent a large group with poorly defined health profiles that could benefit from well-designed health interventions implemented within the civilian healthcare system.

To address gaps in the extant literature and inform interventions and practice at the county level, we estimated the health characteristics and racial/ethnic health disparities among a probation cohort in Hennepin County, using linked administrative records, 1. Our primary aim was to describe the sociodemographic and health characteristics of individuals on probation. Our secondary aim was to compare health characteristics with a national sample using survey data. We hypothesised that individuals on probation would have complex sociodemographic profiles, high health needs compared with general population estimates, and substantial differences in health conditions by race and ethnicity.

\section{METHODS}

\section{Participants and data sources}

We used healthcare claims and administrative probation data to describe health characteristics and disparities among individuals assigned to high-level probation at any point in 2016 with the Hennepin County Department of Community Corrections and Rehabilitation (DOCCR). High-level probation supervision is designed for individuals assessed as being at higher risk of re-offence and assigns one probation officer to oversee 40 individuals on probation. Clients typically meet with their probation officer once a month to discuss compliance with their probation conditions and other needs or problems they might have. We chose to examine individuals on highlevel supervision because they frequently interact with probation officers. Thus, there are more opportunities for modifications to programming and outreach than for individuals on low-level or mid-level supervision. We excluded people on warrant status because warrants are typically issued when someone cannot be located, and thus cannot actively be involved in probation. Individuals were included in our final cohort if they had 6 or more months of enrolment for a full-benefit Minnesota public health insurance programme (Minnesota Health Care Plan (MHCP)) between 1 January 2013 and 31 December 2016 and were adults aged 18 years or older on probation in 2016.

Health and health insurance enrolment data were drawn from claims from any MHCP, but primarily consisted of programmes available through the Affordable Care Act: Medicaid expansion, for individuals with incomes $£ 138 \%$ of the federal poverty level (FPL), and MinnesotaCare, the basic health plan for individual 138\% FPL and $<200 \%$ FPL. Criminal justice data came from multiple sources, including DOCCR probation records, court administrative data and statewide incarceration data. Housing and social service data came from Hennepin County administrative records. Health and criminal justice data were linked using Link Plus to probabilistically match on name and date of birth. Social service and housing data were linked to health data using a county-assigned, personspecific ID.

\section{Patient and public involvement}

Patients or the public were not involved in designing, conducting, reporting or plans for disseminating our research.

\section{Outcomes}

We used International Classification of Diseases (ICD) codes to assess physical health, mental health and substance use diagnoses. ICD ninth revision codes (ICD-9) were used for conditions documented between 1 January 2013 and 30 September 2015 and ICD tenth revision codes (ICD-10) were used for diagnoses documented between 1 October 2015 and 31 December 2016. Chronic Condition Data Warehouse Chronic Condition Categories were used to group diagnosis codes to describe physical and mental health conditions. ${ }^{12}$ Physical health conditions included hypertension, ischemic heart disease, cancer, asthma, arthritis, diabetes, chronic kidney disease, chronic obstructive pulmonary disease and viral hepatitis. We also assessed pregnancy among women of childbearing age (ages 18-44 years) within the last 12 months of ending probation. Mental health diagnoses included depression, anxiety, bipolar disorder, posttraumatic stress disorder, and schizophrenia and other psychotic disorders. The latter category, schizophrenia and other psychotic disorders, we defined as a comparator to National Survey on Drug Use and Health's (NSDUH) estimates of serious mental illness. Substance use disorder (SUD) groupings were derived from Healthcare Cost and Utilization Project definitions. ${ }^{13} 14$ Conditions included alcohol, cannabis, opioid, methamphetamine, cocaine/ crack, sedatives or unspecified/other SUDs. 


\section{Sociodemographic characteristics}

We examined a range of sociodemographic factors including age, gender, race/ethnicity, health insurance enrolment, employment status, education level, number of children and marital status. Health insurance type was determined by any full or partial month of enrolment at any point while on probation in 2016 . Sociodemographic variables, with the exception of health insurance enrollment, were determined based on DOCCR administrative data.

To better understand the non-health care needs of individuals on probation, we also examined use of other safety-net services. We estimated the number of individuals who used a variety of social programmes, including the supplemental nutrition assistance programme, general assistance, temporary assistance for needy families or cash assistance. We also assessed the proportion of individuals who used emergency shelter or supportive housing services.

\section{Statistical analysis}

We first described sociodemographic characteristics among all individuals on high-level probation and then stratified characteristics by race/ethnicity.

Next, we described the proportion of individuals on probation who used social services and housing supports. We examined use of these services at any point while an individual who met our health insurance enrolment criteria was on probation in 2016.

We then analysed the unadjusted prevalence of health conditions among our probation cohort using ICD-9 and ICD-10 codes.

For our general population comparisons, we used the Behavioral Risk Factor Surveillance System (BRFSS) to ascertain the general population prevalence of several physical health conditions in Minnesota. BRFSS is conducted by the US Centers for Disease Control and Prevention and is a telephone-based survey.$^{15}$ We used the 2015-2016 NSDUH for national rates of SUD and mental health conditions in the general population. ${ }^{16}{ }^{17} \mathrm{NSDUH}$ does not provide state-level variables in its public use data file. NSDUH is conducted by the US Substance Abuse and Mental Health Services Administration and is a household survey conducted by a trained interviewer. Both BRFSS and NSDUH are widely used, population-based surveys that are intended to provide national and state-level estimates of physical health, mental health and substance use conditions. Though NSDUH does not contain granular information about mental health conditions, the survey does estimate levels of current depression in the USA, as well as any mental illness and any serious mental illness.

To provide comparisons with disease prevalence data in the general population, we compared rates of physical health conditions among individuals in our probation cohort with the general population in Minnesota using data from BRFSS. Similarly, we compared rates of certain substance use and mental health diagnoses to similar conditions among a national population in NSDUH.
Comparisons between our probation cohort and survey populations were estimated using linear probability models and were adjusted for age and gender to eliminate confounding health risk factors. For comparisons with national data, each observation in the high-supervision probation data was assigned single-unit weight. Weights for observations from national and state survey data were rescaled to match the size of the high-level supervision probation cohort before performing comparisons. We generated predicted probabilities adjusted for age and gender using Stata's margins command and set covariates at mean values of our probation cohort.

Finally, we evaluated rates of health conditions among individuals on probation by race and ethnicity and assessed the significance of these differences after adjusting for age and gender.

All analyses used Stata V.15.1 (College Station, Texas, USA). We considered $\mathrm{p}<0.05$ to be statistically significant.

\section{RESULTS}

Sociodemographic characteristics of individuals on high-level probation

Of the 7992 adults on high-level probation in Hennepin County in 2016, our sample consisted of 5873 adults who met enrolment criteria (table 1). Individuals on highlevel probation in Hennepin County were predominantly young (mean age 35.5 years), male $(80.5 \%$ ) and black or African American (52.9\%). They were unemployed at higher rates than the general public $(38.2 \%$ among individuals on probation vs 3.9\% in Minnesota (not reported in table) $).{ }^{18}$ Among those with available data, the majority had one or more children (72.4\%). Most individuals were enrolled in Medicaid (table 1) while on probation in $2016(80.7 \%)$. Of the individuals enrolled in Medicaid, a majority $(65.9 \%)$ were eligible via Medicaid expansion under the Affordable Care Act. Sociodemographic profiles varied considerably by race and ethnicity (online supplemental file 1).

\section{Social service and housing services among individuals on probation}

Over half of individuals on probation received food support (table 1), and $39.2 \%$ received some form of income support while on probation. General assistance was the most common at $27.1 \%$. Approximately $6.8 \%$ used shelter or supportive housing services while on probation in 2016.

\section{Health characteristics of individuals on high-level probation}

In unadjusted analyses, $35.0 \%$ of individuals on probation in Hennepin County had one or more chronic physical health condition despite a mean age of 35.5 years (table 2). Hypertension (17.3\%) and asthma (14.3\%) were the most common physical health conditions. A majority of individuals had either a diagnosed SUD $(66.4 \%)$ or mental health diagnosis $(55.0 \%)$. Among the diagnosed SUDs, alcohol use disorder was the most 
Table 1 Demographics, public health insurance prevalence and social service use of individuals on high-level probation in Hennepin County, Minnesota, anytime during 2016

Hennepin County probation cohort

n $\quad \%$

\begin{tabular}{lrr}
\hline $\begin{array}{l}\text { Cohort } \\
\text { High-level probation meeting } \\
\text { enrolment criteria }\end{array}$ & 5873 & - \\
Median age & 33.0 & \\
Mean age & 35.5 & \\
Male & 4726 & 80.5 \\
Race/ethnicity & & \\
White, non-Hispanic & 2055 & 35.0 \\
Black or African American & 3104 & 52.9 \\
Native American & 324 & 5.5 \\
Asian or Pacific Islander & 114 & 1.9 \\
Hispanic & 212 & 3.6 \\
Other & 64 & 1.1
\end{tabular}

Health insurance enrolment (while on high-level probation in 2016)

Any Minnesota Health Care Plan 5116

87.1

(MHCP)

\begin{tabular}{|c|c|c|}
\hline Consolidated treatment fund & 1346 & 22.9 \\
\hline Any full-benefit MHCP & 4931 & 84.0 \\
\hline Medicaid & 4742 & 80.7 \\
\hline MinnesotaCare & 5116 & 4.6 \\
\hline \multicolumn{3}{|c|}{$\begin{array}{l}\text { Medicaid eligibility types (among those enrolled in Medicaid in } \\
\text { 2016) }\end{array}$} \\
\hline Expansion & 3126 & 65.9 \\
\hline $\begin{array}{l}\text { Disability, no Medicare/social } \\
\text { service }\end{array}$ & 472 & 10.0 \\
\hline $\begin{array}{l}\text { Disability, with Medicare/social } \\
\text { service }\end{array}$ & 327 & 6.9 \\
\hline Parent & 808 & 17.0 \\
\hline Other & 328 & 6.9 \\
\hline \multicolumn{3}{|l|}{ Employment } \\
\hline Part-time & 1039 & 17.7 \\
\hline Full-time & 1347 & 22.9 \\
\hline Unemployed & 2242 & 38.2 \\
\hline Other & 131 & 2.2 \\
\hline Unknown & 1114 & 19.0 \\
\hline \multicolumn{3}{|l|}{ Education } \\
\hline High school, not completed & 1258 & 21.4 \\
\hline High school, completed & 1360 & 23.2 \\
\hline Graduate Equivalency Degree & 725 & 12.3 \\
\hline $\begin{array}{l}\text { Some college or higher } \\
\text { education }\end{array}$ & 1442 & 24.6 \\
\hline Unknown & 1088 & 18.5 \\
\hline \multicolumn{3}{|l|}{ Children } \\
\hline 0 & 1622 & 27.6 \\
\hline 1 & 998 & 17.0 \\
\hline
\end{tabular}

Continued
Table 1 Continued

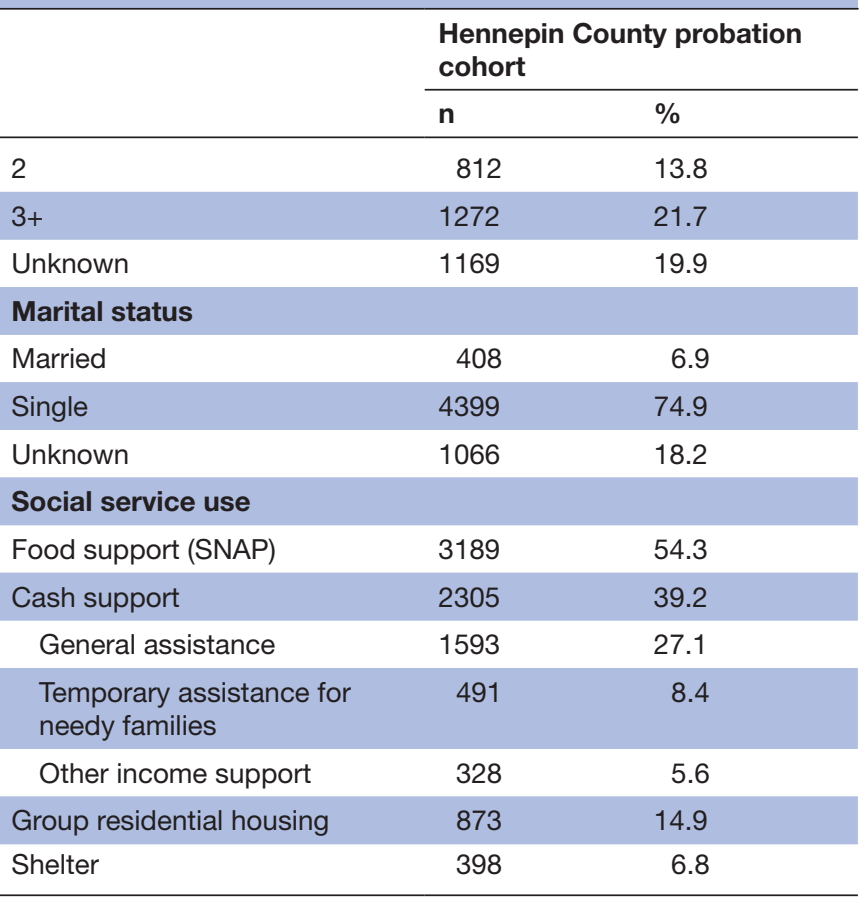

Counts for people on high-level probation anytime during 2016 and with $6+$ months of full-benefit public health insurance eligibility between 2013 and 2016 in Minnesota.

MHCP includes any full or partial month while on high-level probation in 2016. Counts are not exclusive and do not add up to $100 \%$. SNAP, supplemental nutrition assistance programme.

common $(41.2 \%)$, followed by cannabis $(29.0 \%)$ and opioids $(18.3 \%)$. Among diagnosed mental health conditions, anxiety and depression were the most common ( $42.9 \%$ and $41.9 \%$, respectively). Close to half of the individuals on probation had both a diagnosed SUD and mental health condition $(44.9 \%)$.

Health characteristics of individuals on high-level probation compared with general population estimates

In adjusted analyses, individuals on probation in Hennepin County were significantly more likely $(p<0.001)$ to have nearly all physical health conditions measured in this study as compared with the general population in Minnesota, with the exception of arthritis (table 3 ).

Individuals on probation in Hennepin County were significantly more likely $(\mathrm{p}<0.001)$ to have any of the reported diagnosed SUDs $(66.5 \%$ vs $8.1 \%)$, as well as any mental health condition $(55.3 \%$ vs $14.4 \%$ ) compared with a national sample from NSDUH (table 3). Specifically, individuals on probation in Hennepin County were more likely to have a diagnosis of severe mental illness $(12.5 \%$ vs $4.3 \%)$ and depression $(41.6 \%$ vs $9.4 \%)$ as compared with the general population. Individuals on probation in Hennepin County were nearly 20 times more likely to have both a diagnosed SUD and mental health condition compared with the general population ( $44.7 \%$ vs $2.6 \%)$. 
Table 2 Health conditions of individuals on high-level probation in Hennepin County, Minnesota, anytime during 2016

\begin{tabular}{|c|c|c|}
\hline & \multicolumn{2}{|c|}{ Hennepin County probation cohort } \\
\hline & $\mathrm{n}$ & $\%$ \\
\hline Cohort & 5873 & \\
\hline $\begin{array}{l}\text { Women of childbearing age (18-44 } \\
\text { years) }\end{array}$ & 932 & 11.7 \\
\hline \multicolumn{3}{|l|}{ Physical conditions } \\
\hline Hypertension & 1015 & 17.3 \\
\hline Asthma & 842 & 14.3 \\
\hline Arthritis & 513 & 8.7 \\
\hline Diabetes & 346 & 5.9 \\
\hline Cancer & 29 & 0.5 \\
\hline Heart disease & 157 & 2.7 \\
\hline Chronic kidney disease & 337 & 5.7 \\
\hline COPD & 211 & 3.6 \\
\hline Viral hepatitis & 276 & 4.7 \\
\hline \multicolumn{3}{|c|}{ Number of chronic physical conditions ${ }^{\star}$} \\
\hline 0 & 3815 & 65.0 \\
\hline 1 & 1146 & 19.5 \\
\hline $2+$ & 912 & 15.5 \\
\hline $\begin{array}{l}\text { Pregnant in last } 12 \text { months (\% of } \\
\text { women aged } 18-44)\end{array}$ & 99 & 10.6 \\
\hline \multicolumn{3}{|l|}{ Substance use disorders (SUDs) } \\
\hline Any SUD & 3901 & 66.4 \\
\hline Alcohol & 2417 & 41.2 \\
\hline Cannabis & 1703 & 29.0 \\
\hline Opioid & 1074 & 18.3 \\
\hline Methamphetamine & 936 & 15.9 \\
\hline Cocaine/crack & 852 & 14.5 \\
\hline Sedatives & 182 & 3.1 \\
\hline Unspecified/other SUD & 1732 & 29.5 \\
\hline Two or more SUDs & 1957 & 33.3 \\
\hline \multicolumn{3}{|l|}{ Mental health } \\
\hline Any mental health & 3233 & 55.0 \\
\hline Depression & 2461 & 41.9 \\
\hline Anxiety & 2517 & 42.9 \\
\hline Bipolar & 1195 & 20.3 \\
\hline PTSD & 1000 & 17.0 \\
\hline Severe MI & 748 & 12.7 \\
\hline \multicolumn{3}{|l|}{ SUD+MI } \\
\hline Any SUD and any MI & 2635 & 44.9 \\
\hline
\end{tabular}

Counts for people on high-level probation anytime during 2016 and with 6+ months of full-benefit public health insurance eligibility between 2013 and 2016 in Minnesota.

Includes people with violation status, but not warrant status. Conditions from ICD-9 diagnosis codes 2013-Q3 2015, ICD-10 codes Q4 20152016. Physical and mental health conditions grouped according to Centers for Medicare and Medicaid Services Chronic Condition Warehouse specifications. SUD conditions grouped according to Healthcare Cost and Utilization Project specifications, excluding remission codes.

${ }^{*}$ Chronic physical conditions include hypertension, chronic kidney disease, ischemic heart disease, diabetes, cancer, stroke, asthma, arthritis and COPD. COPD, chronic obstructive pulmonary disease; ICD-9, International Classification of Diseases ninth revision; ICD-10, International Classification of Diseases 10th revision; MI, mental illness; PTSD, post-traumatic stress disorder.
Health characteristics of individuals on probation by race/ ethnicity

Among individuals on probation in Hennepin County, black or African American individuals had significantly higher rates of physical health diagnoses when compared with white, non-Hispanic individuals (table 4). Black or African American individuals were less likely to have a diagnosed SUD or mental health conditions when compared with white, non-Hispanic individuals, $(62.0 \%$ vs $71.6 \%, \mathrm{p}<0.001 ; 48.5 \%$ vs $64.9 \%, \mathrm{p}<0.001)$, but had significantly higher rates of several select conditions, including cannabis use $(30.7 \%)$, cocaine use $(17.6 \%)$ and severe mental illness $(13.6 \%)$. White, non-Hispanic individuals had the highest rates of diagnosed methamphetamine use disorders (29.1\%) compared with other race/ ethnicity subcategories. Native American individuals had the highest rates of diagnosed opioid use disorder compared with other race or ethnic groups, with rates nearly double that of white, non-Hispanics. However, white, non-Hispanic individuals had diagnosed opioid use disorder at over twice the rate of black or African American and Asian or Pacific Island individuals. Overall, white, non-Hispanic and Native American individuals had the highest rates of many mental health condition diagnoses.

\section{DISCUSSION}

In this analysis of linked cross-sector administrative data, we found that individuals on probation had complex sociodemographic profiles as well as high rates of chronic physical, mental health and substance use conditions. Individuals on probation had poorer health compared with the general population in nearly every assessed category. Substance use and mental health conditions were particularly prevalent, with $44.9 \%$ of individuals on probation having simultaneous diagnoses for substance use and mental health conditions. These findings add to a growing body of literature that indicates individuals on probation have substantial physical and behavioural health needs, which necessitate access to quality healthcare while on supervision. Additionally, the frequent use of safety-net services highlights the considerable social barriers faced by people on probation. We show that local administrative data can be used to glean important insights about the health of this key population, without requiring primary data collection, and provide more detailed information related to mental health and substance use diagnoses. For example, we quantified the prevalence of specific SUDs and mental health diagnoses to show that use of multiple different substances is common within this population, as are numerous coexisting mental health diagnoses, suggesting that interventions focused on one particular substance or mental health condition may not be effective.

Consistent with previous studies of health in justiceinvolved populations, we found significant health differences between racial and ethnic groups in our probation 
Table 3 Health condition prevalence of individuals on high-level probation in Hennepin County, Minnesota, anytime during 2016, versus general population

Hennepin County probation
cohort, adjusted for age and sex
$(95 \% \mathrm{Cl})$

$\mathrm{n}=5873$

\begin{tabular}{lcc}
\hline Physical conditions & & \\
\hline Hypertension & $17.0 \%(16.0 \%$ to $18.0 \%)$ & $12.5 \%(11.4 \%$ to $13.6 \%)$ \\
\hline Asthma & $14.5 \%(13.6 \%$ to $15.4 \%)$ & $5.5 \%(4.9 \%$ to $6.1 \%)$ \\
\hline Arthritis & $7.8 \%(7.0 \% \text { to } 8.5 \%)^{*}$ & $8.2 \%(7.6 \% \text { to } 8.8 \%)^{*}$ \\
\hline Diabetes & $5.7 \%(5.1 \%$ to $6.4 \%)$ & $3.2 \%(2.8 \%$ to $3.7 \%)$ \\
\hline Chronic kidney disease & $5.8 \%(5.1 \%$ to $6.4 \%)$ & $0.2 \%(-0.1 \%$ to $0.5 \%)$ \\
\hline COPD & $3.4 \%(2.9 \%$ to $4.0 \%)$ & $1.2 \%(0.8 \%$ to $1.5 \%)$
\end{tabular}

\section{Substance use disorders (SUDs)}

\begin{tabular}{lcc} 
Any SUD & $66.5 \%(65.3 \%$ to $67.7 \%)$ & $8.1 \%(7.6 \%$ to $8.5 \%)$ \\
\hline Alcohol & $40.9 \%(39.7 \%$ to $42.2 \%)$ & $6.3 \%(5.9 \%$ to $6.7 \%)$ \\
Cannabis & $28.3 \%(27.1 \%$ to $29.5 \%)$ & $1.7 \%(1.5 \%$ to $1.8 \%)$ \\
Opioid & $17.6 \%((16.6 \%$ to $18.6 \%)$ & $0.7 \%(0.6 \%$ to $0.8 \%)$ \\
Methamphetamine & $14.9 \%(14.0 \%$ to $15.9 \%)$ & $0.2 \%(0.2 \%$ to $0.3 \%)$ \\
Cocaine/crack & $13.2 \%(12.3 \%$ to $14.1 \%)$ & $0.2 \%(0.2 \%$ to $0.3 \%)$ \\
Sedatives & $2.9 \%(2.5 \%$ to $3.4 \%)$ & $0.1 \%(0.0 \%$ to $0.1 \%)$ \\
Mental health & $55.3 \%(54.0 \%$ to $56.6 \%)$ & $14.4 \%(13.4 \%$ to $15.1 \%)$ \\
Any mental health condition & $41.6 \%(40.4 \%$ to $42.9 \%)$ & $9.4 \%(8.9 \%$ to $10 \%)$ \\
$\quad$ Depression & $12.5 \%(11.7 \%$ to $13.4 \%)$ & $4.3 \%(3.9 \%$ to $4.6 \%)$ \\
Severe Ml & & $2.6 \%(2.3 \%$ to $2.8 \%)$ \\
SUD+MI & $44.7 \%(43.4 \%$ to $46.0 \%)$ & \\
Any SUD and any MI &
\end{tabular}

Counts for people on high-level probation anytime during 2016 and with 6+ months of full-benefit public health insurance eligibility between 2013 and 2016 in Minnesota.

Includes people with violation status, but not warrant status.

Conditions from ICD-9 diagnosis codes 2013-Q3 2015, ICD-10 codes Q4 2015-2016. Physical and mental health conditions grouped according to Centers for Medicare and Medicaid Services Chronic Condition Warehouse specifications. SUD conditions grouped according to Healthcare Cost and Utilization Project specifications, excluding remission codes.

Adjusted to age and gender distributions for the high-level cohort. Physical condition comparisons use BRFSS 2015-2016 values for Minnesota, SUD and MI conditions use NSDUH values for the USA.

*Values which were not significantly different. All other values were significant $(p<0.0001)$ based on bivariate statistical testing. BRFSS, Behavioral Risk Factor Surveillance System; COPD, chronic obstructive pulmonary disease; ICD-9, International Classification of Diseases ninth revision; ICD-10, International Classification of Diseases 10th revision; MI, mental illness; NSDUH, National Survey on Drug Use and Health.

cohort. ${ }^{19}{ }^{20}$ Unlike previous national studies which found similar rates of chronic disease among white, black and Native American individuals, we found higher levels of physical health conditions among black and Native American individuals compared with white, non-Hispanic individuals. ${ }^{4}$ However, our findings are consistent with other work using NSDUH that found self-reported mental illness was higher among white, non-Hispanic individuals compared with other racial and ethnic groups. ${ }^{21-23} \mathrm{We}$ build on this work using diagnosed conditions to show that severe mental illness (eg, schizophrenia and other psychotic disorders) was more often diagnosed among black individuals, while lower severity mental illness (eg, anxiety and depression) was less diagnosed compared with white, non-Hispanics. It is important to consider how structural racism may contribute to these differences in physical and mental health conditions and SUDs between racial and ethnic groups. A growing body of evidence points to public policies and institutional practices that perpetuate disparities in who becomes involved in the criminal legal system and how individuals are diagnosed with and treated for their health conditions. ${ }^{24}{ }^{25}$ Future research should consider how policies and practices in the criminal legal and healthcare systems can promote health and reduce inequities among people on probation.

Our findings can inform interventions specific to the unique barriers and opportunities that exist during a period of probation. For example, given the rates of 
physical, mental and substance use conditions, individuals on probation should have the opportunity to connect with a trusted healthcare partner to assess, diagnose and treat underlying medical conditions. These assessments should be free of coercion and should not be predicated on the conditions of supervision. Probation offices should prioritise programmes that help clients enrol in and maintain health insurance, particularly in Medicaid expansion states and social services. Next, the high rates of safety-net service use in our cohort argue for collaboration between healthcare services and community services in order to address unmet needs relating to social determinants of health. Finally, the disaggregation of health conditions by race and ethnicity can inform interventions that recognise and address existing health inequities. For example, because of different rates of specific substance use between racial/ethnic groups, focusing an intervention on only the most prevalent substance use disorder has the potential to disproportionately benefit one racial/ ethnic group and unintentionally exacerbate disparities. Our data suggest that an isolated focus on more prevalent substances, such as opioids or methamphetamine, could unintentionally contribute to and perpetuate racial inequities. Programmes that provide access to treatment for any type of substance use are likely to be more equitable than programmes focusing on a single common substance.

This study has several limitations. First, individuals were only included if they had 6 or more months of eligibility for a full-benefit MHCP in the previous 3 years. Omitting individuals who did not qualify for public healthcare plans could potentially drop individuals who have incomes too high to qualify for such plans. Second, although we controlled for age and gender, our comparison populations of BRFSS for physical conditions and NSDUH for mental health conditions and SUDs were self-reported conditions and we did not have access to diagnosis information for a general population cohort. Third, our study focused on an urban, Midwest county and it is possible that our findings do not generalise when assessed nationally, though they should be comparable with other urban jurisdictions. Finally, while we stratified our findings by race/ethnicity, we do not directly measure the contribution of racism to the disparities we identified.

Our study describes the unique health needs of people on probation and highlights the racial/ethnic differences that exist within this population. By linking local administrative data across public sectors, jurisdictions can identify opportunities to improve programmes and connect individuals to needed resources. This work also highlights the importance of disaggregating diagnoses by race and ethnicity to inform policy decisions. Often overlooked in discussions of correctional healthcare, people on probation represent a key population for whom targeted public health interventions could improve health and address existing inequities. 
Author affiliations

${ }^{1}$ University of Minnesota Medical School, Minneapolis, Minnesota, USA

${ }^{2}$ Department of Emergency Medicine, University of California, San Francisco, San

Francisco, California, USA

${ }^{3}$ Department of Pediatrics, University of Minnesota Medical School, Minneapolis, Minnesota, USA

${ }^{4}$ Health, Homelessness, and Criminal Justice Lab, Hennepin Healthcare Research Institute, Minneapolis, Minnesota, USA

${ }^{5}$ Center of Innovation and Excellence, Hennepin County, Minneapolis, Minnesota, USA

${ }^{6}$ Department of Community Corrections and Rehabilitation, Hennepin County,

Minneapolis, Minnesota, USA

${ }^{7}$ Division of General Internal Medicine, Hennepin County Medical Center,

Minneapolis, Minnesota, USA

Contributors TNAW was responsible for the study design, funding and initial analysis. PB and JW performed the analyses. MO, RJS and TNAW drafted the manuscript. $\mathrm{CH}$ critically revised the manuscript for important intellectual content. All authors read and approved the final manuscript.

Funding This project was supported with funding from the University of Minnesota's Grand Challenges Research Initiative.

Competing interests None declared.

Patient consent for publication Not required.

Ethics approval This study was approved by the Hennepin Healthcare Research Institute Institutional Review Board (Study ID: 18_4509). All data were obtained from pre-existing records and no individual consent was required.

Provenance and peer review Not commissioned; externally peer reviewed. Data availability statement № data are available.

Supplemental material This content has been supplied by the author(s). It has not been vetted by BMJ Publishing Group Limited (BMJ) and may not have been peer-reviewed. Any opinions or recommendations discussed are solely those of the author(s) and are not endorsed by BMJ. BMJ disclaims all liability and responsibility arising from any reliance placed on the content. Where the content includes any translated material, BMJ does not warrant the accuracy and reliability of the translations (including but not limited to local regulations, clinical guidelines, terminology, drug names and drug dosages), and is not responsible for any error and/or omissions arising from translation and adaptation or otherwise.

Open access This is an open access article distributed in accordance with the Creative Commons Attribution Non Commercial (CC BY-NC 4.0) license, which permits others to distribute, remix, adapt, build upon this work non-commercially, and license their derivative works on different terms, provided the original work is properly cited, appropriate credit is given, any changes made indicated, and the use is non-commercial. See: http://creativecommons.org/licenses/by-nc/4.0/.

ORCID iD

Marin Olson http://orcid.org/0000-0002-7531-9839

\section{REFERENCES}

1 Kaeble D. Probation and Parole in the United States, 2017-2018. Bureau of justice statistics, 2020. Available: https://www.bjs.gov/ content/pub/pdf/ppus1718.pdf

2 Zeng Z. Jail inmates in 2018. Bureau of justice statistics, 2020. Available: https://www.bjs.gov/content/pub/pdf/ji18.pdf

3 Carson EA. Prisoners in 2018. Bureau of justice statistics, 2020. Available: https://www.bjs.gov/content/pub/pdf/p18.pdf

4 Phelps MS. Mass probation: toward a more robust theory of state variation in punishment. Punishm Soc 2017;19:53-73.

5 Maruschak L, Minton TD. Correctional populations in the United States, 2017-2018. Bureau of justice statistics, 2020. Available: https://www.bjs.gov/index.cfm?ty=pbdetail\&iid $=7026$
6 Hawks L, Wang EA, Howell B, et al. Health status and health care utilization of US adults under probation: 2015-2018. Am J Public Health 2020;110:1411-7.

7 Winkelman TNA, Phelps MS, Mitchell KL, et al. Physical health and disability among U.S. adults recently on community supervision. $J$ Correct Health Care 2020;26:129-37.

8 Wildeman C, Goldman AW, Wang EA. Age-Standardized mortality of persons on probation, in jail, or in state prison and the general population, 2001-2012. Public Health Rep 2019;134:660-6.

9 Patel K, Boutwell A, Brockmann BW, et al. Integrating correctional and community health care for formerly incarcerated people who are eligible for Medicaid. Health Aff 2014;33:468-73.

10 U.S. reports: Estelle V. gamble, 429 U.S. 97 (1976).Library of Congress. Available: https://www.loc.gov/item/usrep429097/ [Accessed 8/25/21].

1142 USC §1396d, 1965United States Government Publishing Office. Available: https://www.govinfo.gov/content/pkg/USCODE-2010title42/pdf/USCODE-2010-title42-chap7-subchapXIX-sec1396d.pdf [Accessed 8/25/21].

12 Center for Medicare \& Medicaid Services. Condition categories. chronic conditions data Warehouse website, 2020. Available: https:// www2.ccwdata.org/web/guest/condition-categories

13 Heslin KC, Elixhauser A. Mental and substance use disorders among hospitalized teenagers, 2012: statistical brief\# 202, 2016.

14 Owens PL, Fingar KR, McDermott KW. Inpatient stays involving mental and substance use disorders, 2016: Statistical brief\# 249. In: Healthcare cost and utilization project (HCUP) statistical briefs, 2019.

15 Pickens CM, Pierannunzi C, Garvin W, et al. Surveillance for certain health behaviors and conditions among states and selected local areas - behavioral risk factor surveillance system, United States, 2015. MMWR Surveill. Summ. 2018;67:1-90.

16 Center for Behavioral Health Statistics and Quality. 2015 national survey on drug use and health: public use file codebook. substance abuse and mental health services administration, 2018. Available: https://samhda.s3-us-gov-west-1.amazonaws.com/s3fs-public/fielduploads-protected/studies/NSDUH-2015/NSDUH-2015-datasets/ NSDUH-2015DS0001/NSDUH-2015-DS0001-info/NSDUH-2015DS0001-info-codebook.pdf

17 Center for Behavioral Health Statistics and Quality. 2016 national survey on drug use and health: public use file codebook. substance abuse and mental health services administration, 2018. Available: http://samhda.s3- us-gov-west-1.amazonaws.com/s3fs-public/fielduploads-protected/studies/NSDUH-2016/NSDUH-2016- datasets/ NSDUH-2016-DS0001/NSDUH-2016-DS0001-info/NSDUH-2016DS0001-info-codebook.pdf

18 Unemployment Rates for States. U.S. Bureau of labor statistics, U.S. Bureau of labor statistics, 2021. Available: www.bls.gov/lau/lastrk16. $\mathrm{htm}$

19 Larney S, Zaller ND, Dumont DM, et al. A systematic review and meta-analysis of racial and ethnic disparities in hepatitis $\mathrm{C}$ antibody prevalence in United States correctional populations. Ann Epidemiol 2016;26:570-8.

20 Nowotny KM, Rogers RG, Boardman JD. Racial disparities in health conditions among prisoners compared with the general population. SSM Popul Health 2017;3:487-96.

21 Bronson J, Berzofsky M. Indicators of mental health problems reported by prisoners and jail inmates, 2011-12. Bureau of justice statistics, 2017. Available: https://www.bjs.gov/content/pub/pdf/ imhprpji1112.pdf

22 James D, Glaze L. Mental health problems of prison. Bureau of Justice Statistics, 2006.

23 Kaba F, Solimo A, Graves J, et al. Disparities in mental health referral and diagnosis in the new York City jail mental health service. Am J Public Health 2015;105:1911-6.

24 National Academies of Sciences E and Medicine. Addressing the drivers of criminal justice involvement to advance racial equity. In: Proceedings of a Workshop-in brief. The National Academies Press, 2021.

25 Binswanger IA, Redmond N, Steiner JF, et al. Health disparities and the criminal justice system: an agenda for further research and action. J Urban Health 2012;89:98-107. 